\title{
ALEJANDRO KORN Y EL POSITIVISMO
}

\author{
POR \\ ENRIQUE ANDERSON IMBERT \\ Harvard University
}

E1 filósofo argentino que más influencia ha tenido sobre mí - fui su discípulo desde 1927 hasta su muerte- pertenecía a la generación del ochenta: Alejandro Korn (1860-1936) ${ }^{1}$. Mientras lo oía conversar en el aula, en su casa, en el restaurante, en los paseos por la calle, yo lo comparaba con Sócrates. Así como Sócrates, en los diálogos de Platón, aparece apartándose de su propio grupo de sofistas, Korn se apartaba de su propio grupo de escépticos. Por haber sido el más joven de la hornada del ochenta, y sobre todo por su polémica contra el positivismo, Korn los juzgó con excesivo rigor.

La primera señal de disconformidad quedó inédita en su novela Juan Pérez ${ }^{2}$. Escrita alrededor de 1884, retocada en 1910, se publicaría en 1963. La única fecha que la novela indica, y eso como pasado lejano, es la de la revolución de 1874. En ningún momento se alude a la federalización de Buenos Aires en 1880. Sin embargo, hay razones para suponer que los sucesos narrados transcurren en 1881, esto es, durante la primera presidencia del general Roca y en vísperas de la elección del gobernador bonaerense Dardo Rocha. El amor entre Juan Pérez y María O’Ry es un bordado romántico sobre el cañamazo realista del desamor

\footnotetext{
${ }^{1}$ Cuando cito ensayos de Korn me refiero a sus Obras completas (Buenos Aires: Editorial Claridad, 1949). A fin de que el lector que maneja otras ediciones pueda localizar los ensayos los destacaré con las siguientes iniciales: CFC, «Corrientes de la filosofía contemporánea», 1917; DC, "Despedida de la cátedra", 1930; DD, «Discurso del Decanato», 1918; ECFA, «Exposición crítica de la filosofía actual», 1935; FA, «Filosofía argentina», 1927; HM, "Hegel y Marx», 1934; IFEN, «Influencias filosóficas en la evolución nacional», 1912-14; NB, "Nuevas Bases», 1925.

${ }^{2}$ Alejandro Korn, Juan Pérez (Buenos Aires: Editorial Claridad, 1963). Trae un excelente estudio preliminar de Elsa Tabernig.
} 
entre gobierno y oposición. El cañamazo, no el bordado, es lo que ahora nos interesa. En la crónica de una campaña electoral, en un distrito de la provincia de Buenos Aires, Korn describe las malas costumbres políticas de los argentinos de su promoción. El decente pero ambicioso Juan Pérez está dispuesto a trocar su puesto de maestro rural por el de secretario de la intendencia. Para justificar su alianza con un partido desprestigiado le dice al representante de la oposición: «Mis vinculaciones políticas me han dado este puesto, y no se me puede hacer un reproche si cumplo con lealtad» (79). Organiza las fuerzas oficialistas y, contemporizando con sus abusos, las 1leva al triunfo:

No había omitido recurso para asegurar el éxito, había usado todos los resortes oficiales, transigido con todas las flaquezas y tolerado todas las debilidades, pero sólo en aras del interés colectivo, jamás en provecho propio (94). Pero al recordar la causa que había servido, los colaboradores que había soportado, las bajezas toleradas y el fraude final con que se había coronado su obra, sintió lástima de sí mismo, y se hizo reproche por haber malgastado sus fuerzas en una tarea indigna $\mathrm{y}$ estéril (126).

Tan estéril que su propio partido lo deja cesante. Korn no disimula su simpatía por el protagonista Juan Pérez, oficialista, pero tampoco por el deuteroagonista Patricio O’Ry, opositor. Con idéntica ecuanimidad reparte las culpas. En la cuenta del gobierno anota «la corrupción reinante», «las instituciones conculcadas por la camarilla oficial», «el despilfarro de caudales públicos», la presión de los intereses económicos sobre los gobernantes y la de éstos sobre el pueblo, el envilecimiento político de las masas campesinas, el favoritismo, la violencia, el fraude. En la cuenta de la oposición anota los vicios de resentidos, oportunistas, ociosos y egoístas. La actitud de Korn es comprensiva, equilibrada. Cuando más, comenta con ironía «la consecuencia», la constancia y firmeza de convicciones de quienes siempre son gubernistas porque siempre se arriman a «las exterioridades del poder» (52). O con cinismo reflexiona sobre el poder: «Es que sólo el éxito consagra a los hombres, no el vuelo intelectual ni el esfuerzo del ánimo» (113).

Si me he demorado en el examen de esta novela juvenil es porque en ella ya se insinuaban ideas sobre la personalidad y la libre creación de valores que Korn sistematizaría más tarde en sus ensayos filosóficos. $\mathrm{Y}$ a la inversa, los ensayos filosóficos sirven como plano de fondo sobre el que se destacan las figuras de la novela. Por ejemplo: en la novela se alude, sin presentarlos, a personajes importantes de la ciudad, gobernantes, intelectuales, profesionales, funcionarios, capitalistas y especula- 
dores. Pues bien: el comportamiento público de toda esa «gente decente» será juzgada por Korn en su historia de las ideologías en la Argentina.

Es sabido que los intelectuales que en 1880 andaban más o menos entre los veinte y los cincuenta años procedían de viejas y distinguidas familias criollas. Sus padres se habían jugado la vida en las contiendas políticas y, después de la caída de Rosas, contribuyeron a organizar la nación. Es natural, pues, que los hijos se sintieran parte de la clase dirigente, con derechos adquiridos a participar del gobierno. Aun quienes no pertenecían al patriciado argentino se identificaron con su estilo de vida y se mezclaron en el mismo movimiento liberal. Unos más, otros menos, todos preconizaban la ética utilitaria, la educación técnica, la ciencia aplicada, el progreso material. El carácter pragmático del liberalismo argentino explica ciertas contradicciones. Por ejemplo: eran liberales, sí, pero no demócratas; progresistas sin dejar de ser conservadores; escépticos que no dudaban de que los intereses de la burguesía coincidieran con los intereses de la nación. Aunque inteligentes, no profundizaban en los problemas; aunque moralistas, consentían el mal. Eran cosmopolitas, promotores de la inmigración, pero ante el aluvión inmigratorio se les despertó un recelo nacionalista y aun xenófobo. Tal recelo se debía al deseo de salvar el alma nacional, a nociones seudocientíficas sobre razas e inferioridades biológicas o, en el mejor de los casos, al buen sentido, pues era evidente que los inmigrantes, en vez de repartirse por el interior del país, se acomodaban en la ciudad, creando así problemas de difícil solución. Tamaña masa de inmigrantes, nada más que con su presencia, contraproducía en las rancias familias criollas el sentimiento falso de que pertenecían a una aristocracia.

Tal fue la generación del 80 que brilló en las ciudades; y Korn, salido de ella, describió en la novela Juan Pérez el impacto de esa ideología urbana sobre la vida rural. Veamos ahora cómo Korn tradujo el estilo novelesco en términos ensayísticos:

Hombres inteligentes, no podía ocultárseles la discordancia entre los verbalismos corrientes y los hechos reales, entre el énfasis democrático y la perversión profunda de la vida política labrada por la simulación y el fraude. La conciencia de esta dualidad, que alguna vez degenera en duplicidad, les obliga a explicarla y aun a justificarla como una imposición del medio o a construir la teoría ad hoc que reduce las instituciones a una ficción jurídica, a una bambalina para la plebe, tras de la cual se desenvuelve, en un maquiavelismo de pacotilla, la acción de los iniciados. Sin embargro, ni esta posición, al fin realista y defendible, se atrevieron a exponerla con valentía fuera de las tertulias íntimas, siempre amenas, porque los hombres del "régi- 
men» fueron grandes «causeurs». Así llevaron casi a sabiendas al pueblo argentino a su más profunda crisis moral. Nunca ejercieron una acción tutelar o previsora. Contribuyeron a intensificar el concepto materialista vulgarizado, dejaron desenvolverse libre y ciegamente el proceso colectivo sin poner una valla al desborde e indiferentes vieron relajarse todos los vínculos morales. No fue mérito de ellos si la nacionalidad no zozobró en el fango (IFEN, 167).

Obsérvese que Korn echa en cara a los hombres del 80 no tanto su oportunismo - «posición al fin realista y defendible», dice-, sino más bien el hecho de que no filosofaron sobre uel conflicto provocado por un excepcional desarrollo económico en una colectividad de escasa cultura estética y ética» (ibid., 168). Después de todo, Korn, que intervino en las agitaciones cívicas de su tiempo, tuvo que adaptarse a los cambios: militó en los partidos conservador, radical y socialista; incluso llegó a ocupar cargos como los de intendente, concejal y diputado. Sin duda habrá tenido que transigir, como todos los activistas. Sólo que él, a diferencia de sus coetáneos, sí formuló una filosofía de la vida que daba sentido a sus transacciones políticas.

Korn se sentía asociado con los hombres del 80 . Había respirado el mismo aire, leído los mismos libros, presenciado los mismos acontecimientos. En 1930, al despedirse de la cátedra, dijo:

Soy argentino del siglo pasado, es decir, un hombre que ha debido emplear su actividad en los menesteres más diversos antes de recoger su vocación definitiva. $\mathrm{Y}$ he debido ser un autodidacta, porque en nuestro país no había otro medio de dedicarse a los estudios de mi predilección. [...] Soy el último de la generación del 80 [...]; conmigo se clausura un episodio de la vida intelectual del país (DC, 708).

Pero al mismo tiempo que se sentía hombre del 80 no podía menos de enorgullecerse de haber sido, de todos ellos, el que superó el positivismo con una filosofía de la libertad. Es posible que sus primeros desvíos del positivismo determinista coincidieron, precisamente, con la redacción del capítulo sobre «E1 Positivismo», de su historia de las Influencias filosóficas en la evolución nacional ${ }^{3}$. Esto es, después de 1914. Sea

${ }^{3}$ Los tres primeros capítulos aparecieron en revistas (1912-14). El cuarto - «E1 Positivismo»- fue recopilado, junto con los tres anteriores, por la Editorial Claridad, 1937. Según Luis Aznar -- «Apuntaciones biográficas», Alejandro Korn (Buenos Aires: Editorial Losada, 1940)-, Korn «terminó de redactar» este libro en 1919. Probablemente siguió retocando el capítulo cuarto hasta poco antes de su muerte. Coriolano Alberini cuenta que el antipositivismo de Korn sólo se manifestó después de 1913 («Discurso», Actas del Primer Congreso Nacional de Filosofia, 
lo que fuere, lo cierto es que, en Korn, la historia de las ideas ajenas y la exposición de las propias ideas se dieron juntas. Su interpretación del positivismo argentino es, pues, muy personal. Habiendo sido él mismo positivista, es lógico que tendiera a buscar antecedentes del positivismo en la tradición nacional. Proyectaba su propia formación filosófica sobre la de argentinos del pasado. Quizá se excedió al considerar como "positivistas autóctonos» a Alberdi y Sarmiento. Algunos historiadores han aceptado esta inflación del concepto de Positivismo. Es el caso de Francisco Romero ${ }^{4}$. Juan Carlos Torchia Estrada y Norberto Rodríguez Bustamante, si no la aceptan, tampoco la rechazan ${ }^{5}$. En cambio, Korn ha sido rectificado por otros historiadores de la filosofía argentina; historiadores que no siempre tuvieron en cuenta los marcos de referencia que usaba Korn. Por ejemplo, Coriolano Alberini desacredita la interpretación de Korn y, en cambio, declara que la generación de Alberdi fue romántica ${ }^{6}$. Luis Juan Guerrero también desecha el planteo de Korn: la generación de Alberdi, dice, no fue positivista, sino historicista? Arturo Andrés Roig prefiere llamar «espiritualismo» a la orientación de Alberdi y asegura que Korn quiso asimilar dentro de su propio campo positivista a todos los racionalistas románticos ${ }^{8}$. Se trata de desacuerdos meramente semánticos: en la definición de los términos «romanticismo», «historicismo», «espiritualismo», Alberini, Guerrero y Roig incluyen notas que también Korn incluía en el término "positivismo». Como quiera que sea, este tema es harina de otro costal. Estamos estu-

tomo I, Mendoza: Universidad Nacional de Cuyo, 1949). El mismo Korn ha dicho que su formación filosófica fue lenta: leyó la Crítica de la razón pura, de Kant, por casualidad, sólo después de 1897, que es cuando lo nombraron director de un hospital (véase su «Epístola al Cocobacilo», en Obras, 728).

${ }^{4}$ Francisco Romero, «Indicaciones sobre la marcha del pensamiento filosófico en la Argentina», Sobre la filosofía en América (Buenos Aires: Editorial Raigal, 1952).

${ }^{5}$ Juan Carlos Torchia Estrada, La filosofía en la Argentina (Washington, D. C.: Unión Panamericana, 1961); Norberto Rodríguez Bustamante, Alejandro Korn y el problema de la cultura nacional (Universidad Nacional de La Plata, 1960), y La filosofía de Alberdi (ibidem, 1960).

${ }^{6}$ Coriolano Alberini, Problemas de la historia de las ideas filosóficas en la Argentina (Universidad Nacional de La Plata).

${ }^{7}$ Luis Juan Guerrero, Tres temas de filosofía argentina en las entrañas del «Facundo» (Buenos Aires: Imprenta López, 1945). Cfr. Rodolfo M. Agoglia, «Luis Juan Guerrero, intérprete del pensamiento argentino», Cuadernos de Filosofía (Buenos Aires, XV, 22-23, enero-diciembre de 1975).

${ }^{8}$ Arturo Andrés Roig, El espiritualismo argentino entre 1850 y 1900 (México: Editorial Cajica, 1972), y Los krausistas argentinos (ibidem, 1969). Roig sigue a Arturo Ardao, «Alberdi y Korn», Filosofía de lengua española (Montevideo: Editorial Alfá, 1963). 
diando ahora no la historia del positivismo argentino, sino los matices con que Korn pintaba a la hornada del 80 en el cuadro histórico del positivismo ${ }^{9}$.

Equivocadamente o no, Korn creía que el positivismo se había desarrollado en tres generaciones. En la primera, la de los proscriptos, situaba a Alberdi, Sarmiento y Mitre. En la segunda, la de los nacidos poco antes o poco después de Caseros, situaba a los elegantes improvisadores que, con la excepción de Groussac, malbarataron sus dotes: fueron meros ecos de Comte y Spencer. En la tercera generación, la de los universitarios marcados por la revolución de 1890 -revolución de donde han de surgir el radicalismo y el socialismo-, se situó a sí mismo, pero como disidente: mientras otros se aferraban a las doctrinas del determinismo, él las abandonaba. Su programa consistía en minar sus bases dogmáticas. En suma, que Korn estimaba el positivismo de la generación de Alberdi porque había sido auténticamente argentino; y contra el pensamiento determinista, mecanicista, cientificista que vino después levantó una filosofía de la personalidad que, en armonía con el tradicional liberalismo argentino, afirmaba la libertad creadora. Se limitó, pues, a negar a los positivistas del 80 que se habían desentendido del problema de la libertad. Ni siquiera se molestó en individualizarlos con nombre y apellido, razón por la cual nunca estamos seguros de quiénes son las personas a las que se refiere. Sin contar que no es muy claro ni el deslinde entre la segunda y la tercera generación, ni el deslinde entre la tercera y la tanda de antipositivistas que Korn encabezaba. A lo largo de veinte años, Korn repitió sus esquemas sin hacerlos más precisos, como podrá comprobarse en los pasajes que voy a extraer de ensayos de 1919, 1924, 1930 y 1934:

(¿1919?) La segunda generación [positivista] la representan hombres nacidos poco antes o después de Caseros; algunos aún durante el ostracismo de los padres. Es un grupo de hombres cultos y talento-

9 Véanse, sobre los criterios de periodización, Emilio Carilla, Literatura argentina, 1800-1950. Esquema generacional (Universidad Nacional de Tucumán, 1954); Diego F. Pro, Historia del pensamiento filosófico argentino (Mendoza: Universidad Nacional de Cuyo, 1973), y Eugenio Pucciarelli, «Problemas del pensamiento argentino» (Cuadernos de Filosofía, XV, 22-23, enero-diciembre de 1975). Para una visión de conjunto de la generación del 80 y del pensamiento de Korn, véanse E. Anderson Imbert, «Literatura argentina de 1880 a 1910 », en el volumen en prensa del Instituto Torcuato Di Tella, y «La estética de Alejandro Korn», Estudios sobre letras hispánicas (México: Biblioteca del Nuevo Mundo, 1974). No he podido leer todavía el trabajo de Daniel Salazar «Alejandro Korn y la generación del $80 »$, Commemorative series on the Centennial of the Argentine Generation of 1880, edited by H. Rodríguez-Alcalá (University of California: Riverside, núm. 4, 1980). 
sos, universitarios los más, de palabra fácil y de pluma ágil, que, libres ya de toda sugestión romántica, nada propio agregan a las ideas recibidas. Las aceptan como las bases convenidas e indiscutidas de la acción política, ajenos a todo interés filosófico. $\mathrm{Si}$ acaso especularon no fue en el reino platónico de las ideas. [...] Ninguna generación argentina careció como ésta de inquietud espiritual. Padecía el tedio de toda disquisición abstracta. Mal que bien realizaron la tarea del día despreocupados, frívolos a veces; en su escepticismo mantenían tan sólo la fe profunda en los destinos del país, cuyo creciente desarrollo económico podía descontarse de antemano para salvar todos los escollos. [...] El alimento espiritual de estos hombres fue con preferencia los autores franceses contemporáneos. [...] Pero no vieron más que el oropel. [...] Largo tema darán a la historia política del país; la historia de las ideas puede escribirse sin mencionarlos. Las altas funciones que desempeñaron en el gobierno, el brillo con que actuaron en el escenario de la "gran aldea», el merecido prestigio personal de muchos de ellos, han creado en torno de esta generación una leyenda exagerada (IFEN, 166-168).

(1924) La generación subsiguiente [la que sigue a la de Alberdi], llamémosla de Caseros o del Régimen, pese a la leyenda que la considera la más talentosa, no acrecentó este caudal [de ideas] ni se informó del movimiento filosófico extraño. Este interés intelectual se despierta en la tercera generación. El siglo xx nos encuentra todavía bajo la dirección espiritual de los hombres del 80, denominación convenida con la cual distinguimos al grupo de universitarios que alrededor del año 1882 se incorpora a las actividades de la vida pública. De haber triunfado la asonada del noventa ellos habrían asumido la dirección política. Los acontecimientos prorrogaron por más de veinte años el predominio de los intereses creados, y cuando éstos al fin se derrumban, la generación del ochenta pertenecía al pasado. [...] El pecado de los intelectuales del ochenta, hombres de gabinete y de estudio, lo constituye la ausencia de una creación original. Con una cultura superior, con una información más vasta, con mayor probidad intelectual, nos revelaron a Stuart Mill y a Spencer, a Renan y a Taine. El positivismo argentino ya era un hecho cuando ellos juzgaron necesario apoyarlo con el ejemplo europeo (FA, 30).

(1930) Faltaría a la verdad si dijera que aquélla [la del 80] fue la primera generación con verdadera inquietud filosófica. El positivismo argentino tiene un abolengo más remoto, representantes más ilustres y un arraigo secular que no data de la introducción tardía de Spencer. Pero el positivismo casero, vulgarizado y pedestre, había revestido antes de1 90 formas tan absurdas que se imponía la tentativa de regenerarlo por un conocimiento más acabado de la cultura filosó- 
fica europea. En ello se empeñó la generación del 80. A su iniciativa se debió la creación de la Facultad de Filosofía y Letras, [...] en un ambiente hostil y refractario. [...] Tocó a los hombres del 90 una tarea bien penosa. Hagámosle justicia, la realizaron con constancia, con honestidad y, lo que es más, con criterio amplio (DC, 708-709).

(1934) La orientación positivista de la generación de los proscriptos, que después gobernó el país, se convierte en orientación nacional única, que desenvuelven tres generaciones: la primera, la de los proscriptos, traza un rápido cuadro; la segunda está representada por hombres que nacieron alrededor de Caseros. Esta generación pasa ante nosotros como brillante, altamente intelectual, pero desde el punto de vista ideológico es de escaso valor porque no aportó ningún elemento nuevo. Gobernó durante unos treinta años, acompañó con su acción al gran desarrollo económico, pero también contribuyó a la degeneración de los principios positivistas. [...] Cuando actúa la tercera generación, treinta años después de Caseros, comienza a tenerse noticia del positivismo europeo (HM, 575).

Viéndolo bien, la campaña antipositivista de Korn fue justa. Sabía por experiencia propia que el positivismo había enseñado a pensar y a querer con honradez. Después de la trágica caída argentina de 1930, cuando se puso de moda el atacar a la razón en nombre de la violencia y la fe, Korn insistió en recordarnos la deuda que los argentinos hemos contraído con las generaciones positivistas que edificaron nuestra república. En 1933, en la «Exposición crítica de la filosofía actual», denunció «la regresión metafísica» y se atrevió a decir que sólo le parecían respetables las posiciones que continuaban los principios evolucionistas, renovadores, historicistas, empíricos, inteligentes, escépticos y liberales del siglo XIX (ECFA, 483).

Estoy seguro de que hoy, en vista de la nueva "regresión metafísica» que está amenazando la Ley 1.420 sobre educación laica, Korn reconocería la seriedad filosófica de los hombres que la hicieron posible durante la presidencia del general Roca: pienso en hombres como Miguel Cané, Eduardo Wilde, Lucio V. López, Eugenio Cambaceres y otros de quienes Korn nunca se ocupó. 